\title{
CURRENT STATUS OF INTERNSHIP TRAINING IN NEPAL
}

\author{
Santosh Shah, ${ }^{1}$ Anand Kumar, ${ }^{1}$ Kailash Chandra ${ }^{1}$
}

\begin{abstract}
This is a perspective article about the status of undergraduate medical internship training in Nepal based on the learned experience and reflections on current practices on medical education in Nepal. The medical education in Nepal is facing myriad challenges. In order to keep up with the current demands and advances in medical education, adaptation and changes in current curriculum and its modalities are crucial. Current medical curriculum, specifically needs to focus on promoting communication skills, community based learning and medical ethics which may help to garner skills and motivate students for innovations and research in the field.
\end{abstract}

KEY WORDS Internship training, MBBS/BDS curriculum, licensing examination

1. Department of Surgery, Universal College of Medical Sciences, Bhairahawa, Nepal

DOI: https://doi.org/10.3126/jucms.v7i1.24697

\author{
For Correspondence \\ Dr. Sanosh Shah \\ Department of Surgery \\ Universal College of Medical Sciences \\ Bhairahawa, Nepal \\ Email: shahsant366@gmail.com
}




\section{INTRODUCTION}

Nepal Medical Council (NMC) clearly outlines the regulations for undergraduate medical courses including the practice of the principles of medical ethics as one of the core competencies. ${ }^{1}$ Medical ethics is essential for students to develop a rational approach to resolve ethical dilemmas that they may encounter in their medical practices.

Until the date, there have been many reports stressing the significance of incorporating courses on ethical and legal issues in medical curricula. ${ }^{2}$ Although much has been advocated, medical curricula remains to be deprived by an effective courses on medical ethics. ${ }^{3}$ Such a deprivation of medical ethics course in medical curriculum can further facilitate the ignorance and lack of skills to establish themselves as virtuous doctors. ${ }^{4}$ In recent years, studies in other South Asian countries have already emphasized medical ethics to be the part of essential curriculum for undergraduate students.

In the developed world, ethical discussions have advanced towards discussions on issues such as cloning and euthanasia. Unfortunately, in developing world, let alone the discussions on such issues, basic (medical) ethical principles are not practiced in medical field. ${ }^{7}$ For example, allocating a full scale time for patients to understand the medical terminologies and availing all the alternative choices. Having no knowledge on medical ethics, however, cannot obviate medical practitioners from falling into trap of ethical dilemmas. ${ }^{8}$ Therefore, it is critical for medical undergraduates to learn and conceive the principles of fundamental ethical issues. Learning and practicing these principles can have positive impacts on medical students.

A medical college is a tertiary educational institution or part of such an institution that teaches medicine, and awards a professional degree for physicians and surgeons. The quality of medical education is, nevertheless, highly dependent upon the knowledge and skills borne by faculty members. At present, there is a shortage of faculty members in majority of the medical colleges in Nepal. This may further nag the future of medical practitioners. In such a context, it is essential to broaden and revise the current curriculum to upgrade the qualities of teaching in addition to promoting the qualities of faculty members. Here below, we will look at the course curriculum of undergraduate studies, particularly Bachelor in Medicine and Bachelor in Surgery (MBBS) degree.

\section{CURRICULUM}

The MBBS (Bachelor of Medicine and Bachelor of Surgery) course is of four and half year's duration followed by one year compulsory internships at relevant (essential) departments. The salient features of the curriculum are emphasis on common health problems of Nepal, early clinical and community exposure with adequate community based learning and integrated approach in teaching and learning. ${ }^{10}$

The MBBS program aims to produce socially responsible physicians, who are willing and able to meet the existing and emerging challenges of national and international healthcare system. The graduated students are expected to become a highly competent and scientifically literate clinicians, equipped to practice patient-centered medicine maintaining the recent advances in modern medicine.

On completion of the MBBS course and one year of compulsory rotating internship, the medical graduates must acquire the following core competencies. ${ }^{11,12}$

1. Patient care: Must be able to provide appropriate, compassionate and effective treatment of health problems and the promotion of health.

2. Medical knowledge and skills: Must be able to demonstrate knowledge about established and evolving medicine, skills and knowledge on clinical practices so that they can apply for patient care. Must understand the clinical relevance of scientific research and demonstrate the ability to evaluate emerging knowledge and research as it applies to diagnosis, treatment and the prevention of disease.

3. Practice-based learning: Must be able to investigate and evaluate and improve their patient care practices

4. Interpersonal communication skills: Must be able to exchange information effectively with patients, and their families, professional associates and society at large.

5. Professionalism: Must demonstrate a commitment to carry out professional responsibilities, adherence to ethical principles and sensitivity to a diverse patient population

6. Systems-based practice: Must understand the interdependence of the component parts of the healthcare system and appropriately use system resources to provide optimal patient care.

\section{INTERNSHIP}

During one year of compulsory rotating internship, the interns are placed across various specialties such as internal medicine, general surgery, orthopedics, pediatrics, obstetrics and gynecology, anesthesia, trauma and emergency medicine, ophthalmology and otolaryngology. Interns obtain hands-on training in the wards and out-patient departments, where they interact with patients in real time. Besides standard clinical care, the interns also obtain a thorough experience of ward management, staff management, and counseling skills. ${ }^{13}$ They will have self-directed learning to inculcate the habit of lifelong learning. They also have:-

- Problem based learning (PBL)

- Didactic lectures or structured interactive sessions

- Ambulatory teaching in outpatient departments for better exposure and understanding of commonly encountered medical problems

- Bedside teaching learning in wards 
- Acquiring certain clinical examination and procedural skills in a skill laboratory

- Demonstrations, role plays, practice on simulated patients wherever applicable

- Presentation of reports on community diagnosis, family health exercise and district health service management

\section{MEDICAL EDUCATION DEPARTMENT}

In order to make the students learn better, teachers' training programs and continuing medical education (CME) programs should be conducted periodically to update the knowledge of teachers regarding new advances and new teaching methods to facilitate students' learning. The CME workshop should concentrate on the roles and responsibilities of a medical teacher, principles of learning, educational objectives, teaching-learning aids, communication skills, and micro teaching.

\section{EXAMINATIONS}

Nepal Medical Council (NMC) administers the licensing examination to all medical graduates from within and outside Nepal. It conducts exams three times a year. This is a system to check the quality of the interns in the mean time.

After completion of MBBS/BDS course, every medical graduate has to appear in the licensing examination, conducted by Nepal Medical Council. Candidates who are enrolled in university/academy/institution of Nepal and completed minimum six months of their compulsory rotatory internship, are eligible for the licensing examination whereas candidates from abroad must complete one-year compulsory rotatory internship in their respective medical college hospitals to appear in the licensing examination. Nepal Medical Council "Registration Certificate" will be provided to only those candidates who will pass the licensing examination and complete full one year compulsory rotatory internship either from Nepal or abroad. The main objectives of questions of licensing examination:

Multiple choice questions to evaluate the range of knowledge of subject specialty.

Chartered Secretaries Qualifying Scheme (CSQs) to evaluate the depth of knowledge of subject specialty.

\section{COMMUNICATION SKILLS}

Behavioral sciences, ethical issues, information technology and communication skills knowledge have become an essential part of medical education/practice. A communication skills program, to enable the undergraduates to communicate clearly, sensitively, effectively and efficiently with patients, peer sand also with colleagues from a variety of health and social care professions in their clinical and community practice. Good communication enables one to collect information about a patient's problems that is comprehensive, relevant and accurate. It helps to make an accurate, comprehensive diagnosis as well.

\section{COMMUNITY BASED LEARNING}

This is a good approach to learn about the core, norms and values of the society. Being the integral part of the society, medical persons should have the capacity to tackle the diseases prevailing in the community. Few medical institutes in Nepal have the system of exposing the interns in the community level while most do not. Community exposure helps medical doctors to understand the diseases and peoples' perspective towards the disease.

\section{MEDICAL ETHICS}

Healthcare decisions are based not only on clinical and technical grounds, but also on ethical grounds. Through the teaching/learning exercises in this medical ethics module, we aim to instill knowledge, skills and attitudes on the medical students, necessary to guide their conduct and decision making as a practicing doctor. The general aim of this medical ethics module is to help medical students to recognize the importance of being sensitive to ethical issues in day-to-day clinical practice and develop in them the ability to effectively address ethical concerns of patients as well as participants in research.

Regarding the source of knowledge of medical ethics, the most common source was lectures/seminars $(35.7 \%)$ followed by experience at work $(24.5 \%)$, training $(21.4 \%)$ and own reading $(17.3 \%)$. B Shiraz et al reported similar findings in a study among surgical residents and interns in Pakistan. ${ }^{14}$ Another study among medical students in India revealed lecture to be the most common $(54.7 \%)$ source. ${ }^{3}$ Basically, ethical codes and guidelines are the basis for acquiring knowledge on the subject. In a study, almost all $(98.8 \%)$ claimed to know the main contents of Hippocratic Oath. However, only $60.9 \%$ were acquainted with the code of ethics for medical practitioners published by the Nepal Medical Council (NMC). In Karachi, about half of the surgical residents and interns had heard about the Code of Ethics formulated by the Pakistan Medical and Dental Council. ${ }^{14}$ Similar study conducted in the largest tertiary care hospital in Nepal found a significant proportion of medical doctors and nurses were unaware of the three important documents on healthcare ethics: Hippocratic Oath $(33 \%$ od doctors and $51 \%$ of nurses were unaware), Nuremberg code $(90 \%$ of both groups were unaware) and Helsinki Declaration $(85 \%$ of doctors and $88 \%$ of nurses were unaware). ${ }^{15}$ Brief knowledge on the code of ethics is must to have core competencies and be forward as a medical graduate. 


\section{INFORMATION MANAGEMENT}

In order to use information and communication technology to assist in diagnostic, therapeutic and preventive measures and for surveillance and monitoring health status, and also to maintain records of patients for future use and medico-legal purpose, a brief training to our medical graduates is must.

\section{CONCLUSION}

As medical teachers and educationists we should strive to develop the innate talent of future doctors that can help them do better in life, get their creative juices flowing and contribute to the society. Teachers should encourage multiplicity of ideas, richness of thought and acceptance of differing view point. We teachers must allow minds to flower, not atrophy.

The medical education system must give students the courage to question what they learn, infer from intelligent reasoning and become thinking individuals. One definite way is to stimulate their minds and reasoning by throwing ideas at them, so that they will be forced to think, analyze and comprehend.

\section{REFERENCES}

1. Nepal Medical Council. Accreditation Standards for the MBBS (Bachelor of Medicine andBachelor of Surgery) Degree Program for Institutions Admitting 50 Students Annually. http://www. nmc.org.np /information/accreditation-standards-for-the-mbbs50-stundents.html.Accessed 15 October 2015.

2. Mattick K, Bligh J. Undergraduate ethics teaching: revisiting the Consensus Statement. Med Educ. 2006 Apr; 40(4):329-32.

3. Ravindran GD. Medical ethics education in India. Indian J Med Ethics. 2008 Jan Mar; 5(1):18-9.

4. Gordon M S. Teaching and learning medical ethics and law in UK medical schools. Clin Ethics. 5(3):156-158

5. Shirazi B, Shamim MS, Shamim MS, Ahmed A. Medical ethics in surgical wards: knowledge,attitude and practice of surgical team members in Karachi. Indian J Med Ethics. 2005 Jul-Sep ;2 (3) : 94-6.

6. Zoheb R. Bioethics Teaching and Assessment: My Experience of Three Institutes. Bangladesh Journal of Bioethics. 2014; 5(2):4448 .

7. Elger B S, Harding T W. Terminally ill patients and Jehovah's witnesses: teaching acceptance of patients' refusals to vital treatments. Med Educ. 2002; 36:479-488.

8. Hernández González A, Rodríguez Núñez A, CambraLasaosa FJ, Quintero OteroS, RamilFraga C, García Palacios MV. Knowledge of health care ethics in paediatric residents. AnPediatr(Barc). 2014 Feb;80(2):106-13.
9. Sulmasy DP, Geller G, Levine DM, Faden RR. A randomized trial of ethics education formedical house officers. J Med Ethics. $1993 ; 19: 157-63$.

10. Medical education Department, Tribhuvan University Institute of Medicine. Curriculum for Bachelor of Medicine and Bachelor of Surgery (MBBS). Kathmandu, Nepal: Tribhuvan University Institute of Medicine. 2008.

11. Nepal Medical Council. http://www.nmc.org.np

12. Tuladhar TM. Milestones of Nepal medical council in medical education in Nepal. Nepal Medical Council/ Nepal Medical Association. 1995.

13. MBBS Curriculum. Institute of Medicine, 2009.

14. Shirazi B, Shamim MS, Shamim MS, Ahmed A. Medical ethics in surgical wards: knowledge, attitude and practice of surgical team members in Karachi. Indian J Med Ethics. 2005 Jul-Sep;2(3):946.

15. Adhikari S, Paudel K, Aro AR, Adhikari TB, Adhikari B, Mishra SR. Knowledge, attitude and practice of healthcare ethics among resident doctors and ward nurses from a resource poor setting, Nepal. BMC Medical ethics. 2016;17:68. 